\title{
Nuevos textos periodísticos de Pío Baroja recuperados (1901-1930)
}

\author{
Newly Recovered Journalistic Texts \\ by Pío Baroja (1901-1930)
}

\section{Miguel Ángel García De Juan}

Departamento de Lengua y Literatura

IES Rosa Chacel

c/Abizanda 70. Madrid, 28033

Orcid ID 0000-0002-4080-4893

Resumen: La presencia de Pío Baroja en la prensa durante su larga vida fue permanente, bien como colaborador en diferentes periódicos y revistas, bien como persona entrevistada, bien como protagonista de noticias. Después de la búsqueda, hallazgo y publicación en anteriores trabajos de abundantes escritos olvidados del autor vasco, recuperamos en este un nuevo haz de ellos encontrados en varias hemerotecas, tras el seguimiento de diversos rastros de su existencia. Aparte su principal faceta de creador literario, el interés de Pío Baroja por una amplia gama de asuntos queda reflejado otra vez más en casi todos los contenidos de los textos rescatados aquí: política, literatura, relaciones humanas o cinematografía.

Palabras clave: Pío Baroja. Periodismo. Textos recuperados. Variedad temática.
RECIBIDO: 17 DE OCTUBRE DE 2016 ACEPTADO: 5 DE DICIEMBRE DE 2016

\begin{abstract}
Pío Baroja's journalistic activity along his long life was permanent either as an interviewed author or as a main figure in the newspapers. After searching, finding and publishing in previous articles many forgotten writings by the Basque author, and as a consequence of following the different tracks of his life, we publish here a new bundle got from several newspaper libraries. Apart from his main activity as a writer, Pío Baroja's interest in a wide range of subjects appears here clearly: politics, literature, human relationships, cinematography.
\end{abstract}

Keywords: Pío Baroja. Journalism. Recovered Texts. Wide Range of Subjects. 


\section{INTRODUCCIÓN}

— 1 empeño por conocer de la manera más completa a Pío Baroja y hacer pública, en antologías y revistas, la totalidad de su producción periodística no parece encontrar su final. Pensamos, sin embargo, que, después de los caminos recorridos en hemerotecas nacionales y extranjeras, hallando escritos del novelista y comprobando que no pocos de ellos se estamparon cambiados de título en diferentes medios, por voluntad del autor o de manera pirata, el venero de su presencia en la prensa no debe de estar lejos de agotarse.

Acaso quepa recordar brevemente aquí que Pío Baroja publicó su primer artículo en la prensa: "La literatura rusa: los cuentos populares" en La Unión Liberal de San Sebastián, el 10 de febrero de 1890, y el último: "Homenaje de Baroja a Ortega y Gasset", en el $A B C$ de Madrid del 20 de octubre de 1955. Entre ellos aparecieron cientos de textos (artículos, cuentos, fragmentos de novelas, cartas, etc.) en distintos periódicos y revistas. El escritor vasco, mientras vivió, reunió muchos de ellos en libros recopilatorios, desde Vidas sombrías (1900) a La decadencia de la cortesía y otros ensayos (1956). Estudiosos posteriores de su obra, como Manuel Longares o Luis Urrutia, sacaron a la luz otros textos de Baroja desconocidos hasta entonces, en Escritos de juventud (1972) y Hojas sueltas I y II (1973), respectivamente. Pero la más extensa labor de datación (aunque no de publicación) de escritos en la prensa de don Pío, conocidos o no, hasta finales del siglo pasado, la llevó a cabo Beatriz de Ancos Morales en Pío Baroja: literatura y periodismo en su obra (1998). De ella, así como de los hallazgos de Cecilio Alonso y de los nuestros en Desde el exilio (1999), se beneficiaron las Obras completas más recientes del autor vasco publicadas entre 1997 y 1999 por el Círculo de Lectores. Pero, de acuerdo con Juan Carlos Ara Torralba en la "Nota a la edición" al último volumen de estas: "La tarea de recopilación de escritos sigue abierta, pues en años venideros confiamos en que el buen hacer de filólogos e historiadores exhume más textos barojianos" (41-42).

Así pues, se rescata ahora casi una decena de textos desconocidos desde que se publicaron por vez primera entre 1901 y 1930, los cuales aparecerán aquí cronológicamente ordenados y encabezados por números romanos en el apartado segundo de las páginas que siguen, con el objeto de facilitar las referencias a ellos en el primero. ${ }^{1}$

1. Ver también Baroja 2001 y 2003. 


\section{CONTEXTUALIZACIÓN DE LOS TEXTOS RECUPERADOS}

El escrito número I, "Hacia la sombra”, 1901, es el único de carácter estético de nuestro repertorio, pues se trata de un breve relato, hermano de los que su autor escribió en aquellos años de finales del siglo XIX y comienzos del XX y luego reunió en Vidas sombrías (1900) y Cuentos (1919). La aludida breve narración se estampó en Pèl \& Ploma, publicación modernista de Barcelona cuya vida transcurrió entre el 3 de junio de 1899 y diciembre de 1903. Fundada la revista por Ramón Casas y Miguel Utrillo, en un principio fue semanal, después quincenal (cuando publicó Baroja su cuentecito) y, finalmente, mensual. Además de la firma del escritor vasco, pudieron leerse en ella las de Pompeu Gener, Eugenio d'Ors, Santiago Rusiñol, Gabriel Alomar, Ángel Guimerà o Miguel de Unamuno. "Hacia la sombra" participa, en efecto, de la peculiaridad modernista de hallarse en su contenido el estamento aristocrático, la enfermedad, lo grotesco en la figura del niño-envejecido, el misterio y la muerte. Por otra parte, sobresalen dos características de estilo muy presentes en bastantes páginas de las obras de Pío Baroja: la descripción impresionista y la emoción poética.

Por lo que respecta a los escritos II y III, ya Beatriz de Ancos Morales, en su tesis doctoral Pío Baroja: literatura y periodismo en su obra, advertía que no había podido consultar en la Hemeroteca Municipal de Madrid todos los números de la revista de comienzos del siglo xx Fuventud (1 de octubre de 1901 al 27 de marzo de 1902). Los artículos de esa revista descubiertos por De Ancos pasaron a engrosar el volumen decimosexto de las últimas Obras completas del escritor vasco publicadas por el Círculo de Lectores, pero nosotros hemos hallado en los ejemplares que no pudo ver la citada investigadora "El «Viejo Pastor»" y "Víctor Hugo" (Baroja 1997-1999, XVI, 966-1018).

A la fundación de la revista fuventud se refiere el propio Baroja cuando señala que "Azorín" y él, junto al periodista sevillano Carlos del Río, que sería su director, empezaron a elaborar una, a la que pusieron aquel título (Baroja 1997-1999, I, 852-53). Pero más extensamente se han ocupado de esta publicación Luis S. Granjel y María Pilar Celma Valero. El primero señala que el artículo "Con rumbo fijo" estampado el 10 de noviembre de 1901 fue una especie de manifiesto de las ideas de sus creadores y colaboradores, entre los que se encontraban Ramiro de Maeztu, M. de Unamuno, F. Giner de los Ríos, Joaquín Costa, Adolfo Posada, Juan Gualberto Nessi y otros. Celma Valero, por su lado, desgrana muchos detalles sobre fuventud, pero mantiene el error de creer que la firma del último citado es un seudónimo de Pío Baroja cuando, en 
realidad, se trata de su hermano Ricardo Juan Gualberto de la Santísima Trinidad Baroja y Nessi (Sánchez Granjel 214-19; Celma Valero 78-84).

Es en este pesimista contexto político de finales del siglo XIX y comienzos del XX en que se encontraban muchos españoles en el que hay que situar el escrito II de Pío Baroja, "El «Viejo Pastor»" (Fuventud 3 de febrero de 1902). En él muestra su disconformidad con los políticos de izquierdas (Gumersindo de Azcárate), de derechas (Antonio Maura) y volubles como Francisco Romero Robledo. Aunque piensa que el prestigio del "Viejo Pastor", Práxedes Mateo Sagasta, jefe del Gobierno entonces, es superior al de los demás, también cree que detrás del "parlamentarismo y la democracia" en España se "esconden [...] la demagogia y los intereses de la burguesía".

Pío Baroja recordaba a los setenta y tres años que Victor Hugo, del que trata el texto III, fue uno de sus autores predilectos. En efecto, en el segundo volumen de sus "memorias" escribe que al final del bachillerato en Madrid, cuando tenía quince o dieciséis años, sus escritores favoritos eran "V. Hugo, E. Sue, Balzac, J. (sic) Sand, Zola, Espronceda y Bécquer" (Baroja 1997-1999, I, 462-63). ${ }^{3}$ Pero ya en un libro muy anterior, Juventud, egolatría (1917) al referirse a los autores "románticos" había escrito de él: "Victor Hugo, o el más genial de los retóricos; Victor Hugo, o la más exquisita de la vulgaridades; Victor Hugo, o el buen sentido disimulado por el arte" (Baroja 1997-1999, XIII, 378). No obstante, cuando con mayor énfasis trató del autor de Los miserables fue al salir en defensa de sus obras, después de haber sufrido un ataque por parte del obispo de Vitoria, Mateo Múgica Urrestarazu. El indiano José Manuel Ostolaza había fundado en 1928 en Deva (Guipúzcoa) una escuela y biblioteca con vistas a formar posibles emigrantes a América. Transcurridos dos cursos, el prelado Múgica desencadenó una agria polémica a propósito de los libros adquiridos para la biblioteca, entre los que había alguno de V. Hugo, discusión en la que intervino Pío Baroja mediante varios artículos en $L a$ Voz de Guipúzcoa, reproducidos luego por otros diarios. El primero de ellos, 9 de octubre de 1930, página 16, decía:

Monseñor Múgica mezcla en su reprobación los libros más dispares. Habla al mismo tiempo de Blasco Ibáñez, que no es gran cosa, y de Víctor Hugo. Que ha llenado un siglo [...].

2. La dilatada vida política de Sagasta (1825-1903) puede conocerse a través de numerosas y accesibles fuentes. No obstante, cabe recordar que "El «Viejo Pastor»", nombrado así por haberse hecho con la dirección de la "grey" progresista, era una vez más, la séptima, en que desempeñaba la presidencia del Consejo de Ministros (6 de marzo de 1901 al 6 de diciembre de 1902).

3. Ver también Baroja 1997-1999, I, 728-29. 
Monseñor Múgica habla también de las inmundas novelas de Víctor Hugo, lo cual es una sencilla estupidez. Lo único que le legitima es que el Sr. Múgica tampoco ha leído los libros de Víctor Hugo [...].

Los que hemos leído a Víctor Hugo años y años sabemos que era: poeta verbal extraordinario, estilista admirable, retórico genial, poco psicólogo, poco profundo, amigo de contrastes, hombre que daba a todo proporciones grandiosas, al amigo y al enemigo; pero ¿un inmundo?... ¿De dónde? ¿Cuándo? (Baroja 2014, 200-01)

Dicho todo lo anterior en cuanto al interés de Pío Baroja por el escritor galo, se comprenderán mejor sus loas y también sus reproches en el artículo de $\mathcal{F} u$ ventud "Víctor Hugo".

No fue Baroja precisamente un devoto de la milicia, el militarismo y la guerra, pero el 14 de marzo de 1906 La Correspondencia Militar publicaba unas palabras suyas bajo el título de "Bandera, Patria y Estado", nuestro número IV. Dicho periódico, que había salido de las prensas en 1877, tuvo una larga vida hasta su desaparición en 1932. Lo fundó el comandante de caballería Emilio Prieto Villarreal, simpatizante del Partido Republicano Progresista, quien fue también su primer director. A finales del siglo XIX y comienzos del XX el periódico evolucionó hacia posiciones moderadas.

A la pregunta de cuál pudo ser la razón de que este escrito de Pío Baroja apareciera en un medio del mundo militar, se puede responder con la verosímil conjetura de que se debió a que la revista ;Cut-cut!, próxima a la Lliga Regionalista catalana, había ridiculizado al ejército en su número del día 23 de noviembre del año anterior, a propósito de su derrota en Cuba y Filipinas. Al siempre opuesto al independentismo catalán Baroja le pudo más su defensa de la unidad de España frente a la aspiración secesionista de algunos territorios y no tuvo impedimento en contestar a la encuesta de La Correspondencia Militar. ${ }^{4}$ La encuesta de este diario, a la que respondieron también J. Echegaray, Ma-

4. La reacción contra la viñeta satírica de ;Cut-cut! por parte de más de un centenar de militares de la guarnición de Barcelona consistió en asaltar el 25 de noviembre de 1905 los locales de esta revista de La Veu de Catalunya. Es cierto que ;Cut-cut! fue absuelta el 28 de febrero de 1906 de incitación a la rebelión y de insulto a la bandera, lo que, con seguridad, excitó a La Correspondencia Militar a llevar a cabo la consulta cuyas respuestas, entre ellas la de Pío Baroja, recoge el número del 14 de marzo de 1906. Los hechos mencionados abrieron el camino de la elaboración y aprobación de una ley que atribuyó a la jurisdicción militar el enjuiciamiento de las ofensas a la unidad de la Patria, la bandera y el honor del ejército, norma que recibió el nombre de "Ley de jurisdicciones" y que entró en vigor el 22 de marzo de dicho año. Estuvo vigente hasta el 27 de abril de 1931 . 
nuel Bueno, Manuel Linares Rivas, Jacinto Benavente, Jacinto Octavio Picón y otros más, iba encabezada por las siguientes palabras:

Para solemnizar la fiesta militar de hoy, no hemos encontrado otro medio más simpático ni más expresivo que suplicar al elemento civil e intelectual al mismo tiempo nos dispensase la honra de entrar a tambor batiente en nuestras columnas que le abandonamos por completo.

El diario La Mañana, en el que se publicó el texto V, nació bajo la dirección de Manuel Bueno el 5 de diciembre de 1909, un día antes de la presencia en él de Pío Baroja. Su vida se prolongó hasta el 16 de febrero de 1921, si bien el subtítulo con el que partió, "Periódico liberal-socialista", fue modificado en marzo de 1910 por el de "Diario independiente". Colaboraron en él socialistas como Pablo Iglesias y Mariano García Cortés, catalanistas como Gabriel Alomar, periodistas y escritores como Luis Araquistain, Luis Bello o Ramón Pérez de Ayala. ${ }^{5}$ Difícil resulta encontrar en esta relación algún amigo de Pío Baroja, más bien lo contrario.

Ya se ha adelantado que el segundo número de La Mañana ofrecía unas palabras del escritor guipuzcoano bajo el título "Los futuros concejales ¿Qué piensan hacer?". Las encabezaba esta presentación: "Pío Baroja, el ilustre autor de Paradox, Rey (sic) y La brisca (sic), candidato republicano por el distrito del Congreso dice lo siguiente". Pasadas las elecciones del día 12 en las que el candidato por el distrito del Congreso Baroja no fue elegido, publicó La Mañana el día 16 una entrevista bajo el marbete "El deber de la juventud española. Lo que dice Pío Baroja” en la que reitera que no se considera republicano y agrega:

En general el Partido Republicano español, dirigido históricamente por doctrinarios, ha sido una agrupación de retóricos y de pedantes, se ha contentado con hacer frases, con hablar de revolución y con echárselas de terrible. Ha hecho el loco en medio de la risa de todo el mundo. ${ }^{6}$

Por su parte, el periódico El País, subtitulado "Diario republicano", se hizo eco de lo que había manifestado Baroja a Modesto Pérez en La Mañana y publicó el artículo sin firma crítico con don Pío "«Paradox», republicano", al cual respondió este el día 18 con el rotulado "Paradox contesta". En él afirmaba que la entrevista con Modesto Pérez se había realizado antes de las elec-

5. El recorrido y vicisitudes que atravesó La Mañana pueden conocerse con más detalle en Seoane/Sáiz, vol. 3, 95.

6. La Mañana, 16 diciembre 1909, 1. 
ciones, por lo que su publicación ahora solo podía tener la intención de perjudicarlo. Lo cierto es que las palabras de respuesta al entrevistador coinciden con lo que recoge el segundo día de su aparición La Mañana, las cuales reproducimos aquí en nuestro número V: "Si soy concejal, me ocuparé con gusto de los asuntos del Ayuntamiento, pero sin tener ningún entusiasmo místico para sacrificarme por él, ni mucho menos". Pues lo principal para él es escribir, labor con la que se gana la vida. Con todo, como se sabe, Pío Baroja no dejaría de pertenecer al partido Republicano Radical hasta el 11 de agosto de 1911, cuando envió al director de El País, Roberto Castrovido, el escrito que el diario publicó con el rótulo "Latigazos de Baroja: sálvese el que pueda". El remitente exponía que lo abandonaba a causa de su desacuerdo con Lerroux por no intentar que se evitara el ajusticiamiento del fogonero de la fragata $\mathrm{Nu}$ mancia Antonio Sánchez Moya, al haber encabezado un motín a bordo del buque en los primeros días de dicho mes.

Al final de la Primera Guerra Mundial La Grande Revue francesa llevó a cabo una "Enquête mondiale sur l'avenir de la littérature". La respuesta de Pío Baroja la recogemos aquí encabezada por el número VI.?

La mencionada revista presentaba al escritor como "l'homme aux paradoxes", una de las cuales era su germanofilia. Además, desde el punto de vista literario lo consideraba hermano de Gorki y observador de los bajos fondos de España. Por lo que atañe a la germanofilia, que no germanomanía, de Baroja hemos escrito ya numerosas páginas orientadas a matizar un tópico que se repite con pertinaz frecuencia, incluso por personas especializadas o aparentemente expertas en la vida, ideas y obras del escritor vasco. Para no extendernos, repetimos aquí tres datos elocuentes de su pensamiento y conducta durante la Gran Guerra: primero, la ausencia de su firma en los manifiestos a favor o en contra de uno u otro bando; segundo, la larga respuesta a la periodista francesa Renée Lafont en 1915 que comienza: "Dire ce qu'on pense de la guerre est très difficile, quand on est belligérant, et ne l'est pas moins quand on est Neutre"; 8 tercero, la noticia que daban varios periódicos el día 5 de diciembre de 1916:

Zaragoza. (Lunes, noche) Han marchado a Madrid Pío Baroja y el caricaturista Bagaría, que vinieron para rogar a los artistas aragoneses envíen

7. La respuesta de Baroja iba seguida de la de Vicente Blasco Ibáñez.

8. La Renaissance politique, littéraire et artistique, 20 marzo 1915, en Lafont 17. Renée Lafont preguntó a Pérez Galdós, Blasco Ibáñez, Alberto Insúa, Pérez de Ayala y otros. Dividió las contestaciones en aliadófilas, germanófilas y neutrales. Entre estas últimas ubicó la de Pío Baroja. La respuesta completa del escritor vasco puede leerse en Baroja 2014, 184-86. 
obras a la Exposición que se organiza en beneficio de los españoles que forman parte de la legión extranjera agregada al ejército francés. ${ }^{9}$

Volviendo a la contestación de don Pío a La Grande Revue que recuperamos ahora, se advierte con claridad cuál era su deseo, después de haber criticado con dureza a uno y otro bloque contendientes: "Un grand amour pour la paix" y que sirva de estímulo para pensar en asuntos tan esenciales en la vida como el amor y la amistad.

Los dos textos de Pío Baroja que se transcriben a continuación con los números VII y VIII participan de un denominador común: la filmación en 1928 de una película basada en su novela Zalacaín el aventurero. El primero, publicado el 2 de abril en El Progreso, corresponde a un tiempo algo anterior a su rodaje y el segundo a su plena grabación. Aquel, titulado "Pío Baroja habla de mujeres, hombres y cine", lo aprovecha el autor para tratar de los jóvenes y la relación con sus padres y las mujeres, y también de los cambios en el comportamiento de las chicas y la comunicación de estas con los muchachos. El texto VIII, que se estampó en El Pueblo Vasco de la edición de San Sebastián, el 12 de agosto de $1928,{ }^{10}$ copia unas cuartillas leídas a los postres de un banquete celebrado en la Sociedad de Irún con ocasión del rodaje de la citada película. Afirma Baroja que, al llevar la novela al cine, esta adquiere una naturaleza distinta; o sea, se produce una recreación artística. Ahora la obra deja de estar vinculada al autor para estarlo con los intervinientes en la recreación. De este modo "hoy -dice don Pío- ya no le considero a [Zalacaín] como hijo mío, ni aun como allegado, sino como algo extraño y lejano a mí, y realmente así es. Perico Larrañaga, que lo representa y le da nueva vida en la pantalla, está más cerca de él que su autor". ${ }^{11}$

9. La Correspondencia de España, 5 diciembre 1916, 3.

10. Este diario lo fundó Rafael Picavea y Leguía el 1 de agosto de 1903 y comenzó a dirigirlo Herminio Madinaveitia. Aunque se declaraba independiente, tuvo una inclinación monárquica. Al llegar la Segunda República española se situó de su lado. En El Pueblo Vasco donostiarra también escribieron R. de Maeztu y José Martínez Ruiz (“Azorín”). Pío Baroja colaboró en él en la segunda parte de los años 1903 y 1904. Su primer artículo, "Al llegar", 3, se publicó el mismo día en que se anunciaba en la primera página su colaboración durante un corto tiempo. Cuando se estamparon las cuartillas leídas en el banquete de la Sociedad de Irún "Los chapelaundis: Zalacaín el aventurero visto por Pío Baroja", se hallaba al frente del diario Felipe Urola, bajo cuya dirección desapareció en 1936.

11. A esta reunión de los "chapelaundis" de Irún se refiere Pío Baroja en 1997-1999, II, 968-69, aunque se equivoca al ubicarla "hace treinta años", pues, en realidad, hacía veinte. Más información sobre el rodaje de Zalacaín el aventurero y la atención que le prestó su autor puede obtenerse leyendo a Sánchez-Ostiz 230-33. 
Finalmente, el texto olvidado de Pío Baroja número IX, La Prensa. Diario de la mañana, 12 de noviembre de $1930,{ }^{12}$ versa sobre aficiones por las que no sentía ninguna atracción, entre ellas, la llamada "fiesta nacional", la cual fue objeto de su crítica en no pocas ocasiones. A modo de ejemplo, recordamos el artículo "Baroja contra los toros: el caso de Briviesca", aparecido en El Mundo el día 10 de agosto de 1909, en donde alababa el acuerdo del Ayuntamiento de esta localidad burgalesa de no celebrar corridas de toros ese año, en las fiestas del 15 y 16 del referido mes. ${ }^{13}$

TEXTOS RECUPERADOS

$$
\begin{gathered}
\text { I } \\
\text { "Hacia la sombra" } \\
\text { (Pèl \& Ploma -edición castellana-, } 1 \text { de enero de 1901: 8) }
\end{gathered}
$$

En la sala grande y suntuosa del vasto palacio, pasaba el heredero los días torturados de su triste infancia.

En el sillón, junto a la ventana, el niño, acompañado de su madre, silencioso y pensativo, miraba con sus ojos profundos de viejo triste el juego de las sombras con los tapices de la sala y veía a través de los cristales el cielo pálido cruzado por nubes blancas de los días de otoño, y los árboles de una plazoleta lejana desnudos de follaje, con algunas hojas amarillentas que tiritaban de frío...

Aquella tarde, al obscurecer, el niño envejecido y raquítico, con los ojos profundos, inflamados por la fiebre, contempló durante largo tiempo, desde la ancha ventana, las luces brillantes de un crepúsculo lleno de esplendores. Por el cielo azul de nácar, estriado de rojo, nadaban nubes incendiadas, nubes blancas; el humo negro de alguna fábrica iba lentamente subiéndose en el aire.

$Y$ el niño dijo:

-¿Qué hay, madre, allá arriba?

Y la madre replicó:

-¿En dónde, hijo mío, en el cielo?

-Sí.

-Nubes, nubes; no hay otra cosa.

12. Este periódico de Santa Cruz de Tenerife había nacido en 1910 con el subtítulo de "Diario Republicano", el cual fue cambiando hasta su desaparición. En 1930 recuperó de nuevo un título secundario, pero ahora el de "Diario de la mañana".

13. El artículo puede leerse en Baroja 2014, 153-55. 
-¿Y nada más?

-Nada más.

El niño no contestó; poco después se acercó a su madre, se subió a su regazo, y en voz baja murmuró, señalando las nubes bajas que cruzaban el azul del cielo:

-Yo quisiera ir allí, allí. ¿No podrá ser eso, madre?

-No, hijo mío.

-¿Por qué?

-Porque allí no hay más que nubes. No hay otra cosa.

Pero el niño señaló a su madre, allá, un dragón rojo que iba corriendo entre llamas, en otro lado un cisne, en otro una ballena larga y triste, en otro un gigante con un inmenso arco para disparar flechas.

Y la madre oía las palabras de su hijo y miraban los dos ansiosamente el cielo del crepúsculo.

Luego las nubes fueron tornándose cenicientas con la proximidad de la noche y el niño mostró a su madre, arriba en el cielo, una gran vía entre campos de color de acero.

Era un paisaje gris, todo estático e inmutable; una vía inmensa de aguas negruzcas, desembocaba a lo lejos, en el mar inmóvil y sin olas, bajo un horizonte rojo y espléndido, y por las aguas de la vía, pasaban lenta, muy lentamente, una tras otra, barcas cuadradas, negras, blancas, algunas cubiertas de flores.

En la orilla desolada vieron madre e hijo una dama hermosa y sonriente como la Primavera. Y el niño, envejecido y raquítico, se acercó a ella y le pidió con voz quejumbrosa que le dejara marcharse en una de las barcas cuadradas que flotaban sobre la vía.

Y la dama dijo:

-Hijo mío, no huyas de mí; tu madre va a llorar mucho si te vas. No conoces todavía mis dominios. Yo tengo aquí regiones llenas de luz y de flores, tengo hermosos jardines y árboles con manzanas de oro.

Y el niño contestó sonriendo con una sonrisa de viejo, señalando las nubes rojas del crepúsculo:

-Yo quiero ir allá, señora.

-Hijo mío -repuso ella-; no vayas. La vida será para ti un Edén. Tendrá lo que desees, alegría, felicidades...

-No, no, -replicó el niño-. Mis huesos están cansados; la vida es triste. Ponme en una de esas barcas que van por el río. 
-Esas barcas son ataúdes que llevan a la Muerte.

-iQué importa! Yo quiero ir allá.

-No vayas. Aquí hay luz, allá obscuridad. Esas nubes rojas te engañan; no son más que sombras.

-iQué importa! Soy hijo de las sombras y quiero ir a ellas.

-Vete, pues, si es tu deseo.

Y la dama colocó al niño en un ataúd blanco y cubrió su cuerpo de flores, flores tristes de la orilla, y la extraña barca se perdió..., allí donde se encienden las nubes rojas del crepúsculo, donde la imaginación levanta góticas catedrales; allí, donde las grandes sombras de lo Desconocido duermen acurrucadas como esfinges a los pies de lo Absoluto.

$\mathrm{Y}$, al hacerse de noche, la madre besó a su hijo en la frente. Y la frente estaba fría como el mármol.

Pío BAROJA

\author{
II \\ "El «Viejo Pastor»" \\ (Fuventud 8, 23 de febrero de 1902: 14)
}

En el Congreso se discuten los acontecimientos de Barcelona. Azcárate ataca al Gobierno por haber suspendido las garantías constitucionales. Maura le acusa de no tener prestigio. Romero Robledo opina que en Barcelona ni en ninguna parte hay cuestión social. No hay más que cuestiones de orden público y, después de este descubrimiento sorprendente y de dirigir una invocación solemne al Altísimo para que guarde al Rey, a la Reina y al sagrado capital, se sienta el hombre tan convencido de que ha dicho algo.

Habla Sagasta y se persuade uno de que a pesar de su edad y de sus achaques es el único hombre con sentido común de todos los que se sientan en los bancos de ese charladero de la plaza de las Cortes.

$\mathrm{Si}$ (sic) solo en los países con gobiernos desprestigiados -le dice a Maura- hay huelgas como la de Barcelona, Francia, Italia, Bélgica, Austria, tienen y han tenido gobiernos desprestigiados. A Romero, que le acusa de no haber suspendido antes las garantías constitucionales, le pregunta lo que hubiera opinado Azcárate de esta decisión cuando ahora le parece prematura.

El viejo está en lo cierto, argumenta mejor que los contrarios. ¿No hay gobierno? -les dice-. Bueno estaría este país si pasara tres días sin gobierno. Y 
tiene razón. Pero cuando Sagasta habla de que hay que estudiar estas cuestiones sociales, se convence uno de que habla para salir del paso. ¿Estudiarlas? No estamos ya en el caso de estudiarlas, sino de resolver esas cuestiones.

Para eso no se necesitan grandes estudios, ni grandes conocimientos: basta la voluntad y la buena fe.

Y la burguesía actual para atrofiar las voluntades, para impedir la buena fe, ha inventado el parlamentarismo y la democracia.

Pío BAROJA

$$
\begin{gathered}
\text { III } \\
\text { "Víctor Hugo" } \\
\text { (Fuventud 9, } 2 \text { de marzo de 1902: } 2 \text { y 3) }
\end{gathered}
$$

En el Olimpo de los dioses mayores no me parece poeta, ni novelista, ni filósofo; pero me parece siempre admirable.

Víctor Hugo es una especie de Polifemo con gran pupila artística; tiene ritmos misteriosos en sus versos y una gran fantasía. Con estas condiciones geniales, parece necesario producir grandes cosas; libros eternos. Víctor Hugo no los ha hecho; su obra se disuelve por el tiempo. Esta gran pupila que percibió grandezas, que presentó ideas en lucha y elementos en lucha; que reflejó pirámides, catedrales, rayos, tempestades, no pudo coger la vida; la vida era un reptil que se le escapaba de sus manos de bronce. Quiso cogerla, agarrarla, infundirla en sus obras; esculpió sus estatuas y las estatuas no se animaron, o, si se animaron, fue con una vida artificial y monstruosa. La humanidad en Hugo fue monstruosidad; su cerebro paría ideas o paría monstruos. El monstruo en Víctor Hugo es tan necesario como el loco en Shakespeare y el místico en Tolstoy.

Los tipos de Víctor Hugo son una galería de monstruos; es más bien el tipo de Hugo una hidra de cien cabezas, un monstruo lleno de anillos: nace en el negro Bug Jargal, se desarrolla en Han de Islandia y toma ya su forma definitiva en Quasimodo de Nuestra Señora. Desde aquí las hipótesis del monstruo son variadísimas: jorobado, burlón y canallesco en Triboulet, deforme y bueno en Guymplame, malvado en Balkiphedro, severo en Javert, piadoso en Jean Valjean, austero en Cimourdam y en Enjolras, misántropo en Ursus.

Todos estos monstruos viven rodeados también de monstruos, ya sean comprachicos, ya bandidos de las alcantarillas de París, y todos viven envuel- 
tos en una furia continua de los lamentos materiales y morales. Como contraste a la nota negra hay la nota blanca: doña Sol, Dea, Cossette, Fantina, pero la nota blanca parece casi siempre tan falta de vida real como la negra. Hugo, más que grande, es magnífico, majestuoso; sus tipos son fantásticos, el medio en que se desarrollan es también fantástico, su magnificencia es también fantasmagórica.

Víctor Hugo es un gran escultor de arte gótico. Su entusiasmo por Nuestra Señora de París se concibe admirablemente en su temperamento. Él ve las líneas, las masas, las construcciones grandes; quizás más que escultor era arquitecto. En algo se parece a Zola; pero Zola es más sensual. Zola pinta a grandes pinceladas, Víctor Hugo esculpe a grandes martillazos; Zola tiene color y las líneas se le pierden; Víctor Hugo tiene líneas y nunca color; Zola es un veneciano del Renacimiento; Hugo es un francés de los que hicieron las primeras catedrales góticas del mundo en la Isla de Francia.

El arte debe a Víctor Hugo su emancipación de la rutina; le debe el que la humanidad comenzase a aprender la belleza de las ojivas góticas; el pensamiento le debe un paso grande en su liberación.

Tras de la apoteosis de Hugo, ha venido la época de las negaciones y al poeta se le ha negado todo. Hoy es moda negar a Víctor Hugo, para afirmar a unos cuantos saltimbanquis de las ideas y las palabras: Mallarmé o Loti.

En nuestro siglo, en el XIX, no han podido engendrarse grandes héroes literarios; las creaciones han sido mayores en número y menores en intensidad. A esa creación hecha por el hombre en este siglo han contribuido casi todos los grandes escritores con más éxito que Hugo.

Los tipos de Dickens, de Ibsen, de Tolstoy, quedarán por encima de los de Hugo; pero las frases de Hugo quedarán por encima de las de Dickens, de las de Ibsen y de las de Tolstoy. Víctor Hugo es en el fondo un gran retórico.

PÍO BAROJA

IV

"Bandera, Patria, Estado"

(La Correspondencia Militar, miércoles 14 de marzo de 1906: 2)

Si la bandera más que la Patria representase el Estado con su fuerza, con sus instituciones, con sus leyes, con su política y sus ministros, yo, por mi parte, no la amaría. 
Pero la bandera representa la Patria, las tierras soleadas de España, representa los esfuerzos de nuestra raza, que hoy vive pobre y miserable en los campos, embrutecida por el fanatismo y la ignorancia, saqueada por los ricos, dominada por los oligarcas, engañada por todos.

$\mathrm{Y}$, aunque hemos visto nuestra bandera sirviendo los intereses de los potentados, y de motivo para cierta cursilería lírica de políticos y de poetas, aunque la hemos visto llevando a morir a las colonias a los hombres de nuestro terruño, la seguimos amando, porque es el símbolo de la tierra, de la raza, que, aunque descastada en las alturas, en donde se habla de patriotismo, es alta y noblemente española en los rincones, donde se vive sin protección ninguna y en donde solo se siente de la Patria la acción deletérea del Estado.

Pío BAROJA

\author{
$\mathrm{V}$ \\ "Los futuros concejales. ¿Qué piensan hacer?" \\ (La Mañana. Periódico liberal-socialista, lunes 6 de diciembre de 1909: 3)
}

Es difícil decir en un plazo tan perentorio lo que uno puede hacer en el caso de ser elegido concejal.

Por de pronto, no seré de los concejales elocuentes.

Hemos tenido en España demasiados oradores brillantes que nos han contado de una manera lírica las bellezas de la libertad, de la democracia y de la civilización, y, sin embargo, cuando un español independiente se pone a discurrir, duda de si seremos libres, de si seremos demócratas y hasta de si seremos civilizados.

Rousseau decía que el hombre que piensa es un animal depravado; yo creo que el hombre que habla por el gusto de hablar en retórico es un crítico que para lo único que puede servir es para vocear en un cinematógrafo.

Yo, por mi parte, si entro a formar parte del Ayuntamiento de Madrid, haré una labor de información, parte por gusto y parte por hacer un servicio al pueblo en donde vivo.

Ayudado por los medios que pueda dar el Municipio, quiero saber cómo se vive en Madrid, cómo se nace en Madrid, cómo se muere en Madrid.

Saber los males de la ciudad y exponerlos hablando o escribiendo, este será mi principal objeto. 
Una advertencia tengo que hacer; desde que me nombraron candidato a concejal, oigo a muchos que dicen: "Sí, hay que trabajar en el Ayuntamiento sin descanso, hay que trabajar día y noche".

Yo tengo que confesar a mis electores que no pienso hacer tal cosa. Yo soy escritor, y lo poco que gano lo gano escribiendo, y no pienso dejar de ser escritor para vaciarme en ser concejal.

Yo, si soy concejal, como si no lo soy, primero seré escritor. Me parece pedirme demasiado altruismo el que abandone mis asuntos para dedicarme solamente a los asuntos municipales. ¡Y a mí, que tengo el individualismo vasco, remachado con el individualismo particular mío!

No, yo lo que prometo es que, si soy concejal, me ocuparé con gusto de los asuntos del Ayuntamiento, pero sin tener ningún entusiasmo místico para sacrificarme por él, ni mucho menos.

Ahora, sí que no vendrá a mí nada de la Casa de la Villa, no recibiré ni una entrada de teatro, ni un pase de tranvía, ni un regalo, sea grande o sea insignificante. Si me los mandan, pienso devolverlos todos.

Y no por austeridad, porque yo me río de la austeridad.

PíO BAROJA

$\mathrm{VI}$

"Enquête mondiale sur l'avenir de la littérature"

(La Grande Revue 98, diciembre 1918: 195-96)

Je ne crois pas à l'influence de la guerre sur la littérature universelle. La guerre aura une profonde répercussion sur l'économie, l'industrie, la politique; elle atteindra les zones du journalisme et de la sociologie, mais ne s'étendra pas au-delà. La science, la philosophie et l'art demeurent, dans leur partie la plus pure, en dehors de l'action des baïonnettes et des canons, et de l'esprit des hommes qui les manipulent.

La guerre fournira peut-être quelques nouveaux éléments à la littérature, mais ces éléments seront en quelque sorte des éléments extérieurs qui n'altèreront pas son essence.

En ce qui me concerne, je n'ai jamais cru que la guerre ait influé par ellemême sur l'évolution de la pensée. En d'autres époques elle aura pu apporter des idées nouvelles, des conceptions inconnues d'un pays; aujourd'hui il ne peut en être ainsi. 
Tandis que le canon tonnait à Iéna, Hegel écrivait la Phénoménologie de l'Esprit, et Goethe terminait la première parti de Faust.

L'influence de la guerre de 70 sur les écrivains français et allemands, chez les uns orgueil du triomphe, chez les autres sentiments de vengeance, n'a laissé aucune empreinte artistique quelconque; par contre, la curiosité humaine de Stendhal dans la bataille de Waterloo, la sérénité olympique de Tolstoï, décrivant les scènes de la guerre et de la paix en Russie, ont produit des pages inoubliables.

Je ne crois pas qu'il puisse naître de la guerre une Renaissance classique ou romantique; pour moi, le classicisme et le romantisme existent dans le fond du tempérament. L'homme se consacre à Apollo ou à Dionysos selon ses instincts.

De la guerre il résultera, selon moi, un grand amour pour la paix, un désir de sociabilité, un certain éloignement de la politique, une soif avide de s'instruire des choses spirituelles, essentielles et élémentaires de la vie, comme l'amour, l'amitié, le problème éternel...

Pío BAROJA

\author{
VII \\ "Pío Baroja habla de mujeres, hombres y cine" \\ (El Progreso: diario republicano autonomista, Santa Cruz de Tenerife, \\ lunes 2 de abril de 1928: 1)
}

Voy a conocer un mundo para mí completamente nuevo. Apenas se supo que se iba a filmar una de mis novelas, comenzó por mi casa el desfile de peliculeros. Cosa divertida. Me dan consejos: que no recomiende a este actor, que aquel es más plástico que el otro; que si este tiene los ojos demasiado saltones; que el otro tiene los labios muy gruesos para filmar... Nada, que me ofrecen ojos, labios y pestañas al por mayor y al detail. Este mundo de la pantalla puede dar mucho de sí. No sé si Zalacain me va a dar dinero; uno ya está viejo y le quedan pocas ilusiones. Lo que sí sé es que la juventud actual entra en la vida con una alegría que no tuvieron sus padres ni sus abuelos. Hay en los jóvenes de ahora optimismo; creen o, por lo menos, hacen que se lo creen que todo el mundo tiene en parte su merecido en la tierra. A esto añaden un pensamiento convertido en consigna, según el cual hay que trabajar mucho para ganar mucho y para gastar mucho. Imponen y ex- 
tienden el sentido práctico. Los ingenieros prefieren hacer obras de ingeniería que no versos o comedias, y los médicos prefieren un estudio clínico a observaciones sobre la vida. Ni sueñan ni les interesan los sueños de los demás. Ni lo que otros soñaron. Pero yo pregunto en qué se van a reflejar esos jóvenes cuando lleguen a viejos y se encuentren sin poder soñar. Yo voy creyendo que la juventud actual no tiene aires de juventud artística. En los jóvenes hay afición pero no hay misticismo del arte. Dije una vez en una conferencia que no creo que la juventud actual se sienta representada por un poeta dadaísta y por un pintor cubista. La mayoría de los jóvenes se burlan de esas manifestaciones de una extravagancia comercial y no le dan mucha importancia. Tampoco creo que presten mucha atención a esas entelequias de mala sombra de Pirandello. Por, de pronto, tienen un trato cordial y miran a sus padres como hombres algo absurdos y exagerados y disparatadamente románticos, pero les profesan antipatía, porque tampoco les estorban en nada.

Con las mujeres tienen más amistad y más camaradería que sus padres. Llevan una vida más social y han dejado a un lado, si es que no lo han echado por la borda, el misticismo por el eterno femenino, que a los de nuestra generación nos impelía a hacer un sinfín de tonterías y necedades.

También ellas, las de ahora, son muy distintas de nuestras madres y abuelas. Hoy las mujeres se han humanizado en sus ideas y en su indumentaria. Sin duda, la mujer actual ya no está en pie de guerra, y si no está (sic), lo está de otra manera. Han echado el corsé a las zarzas, y hablan, bailan y guían los automóviles de modo graciosísimo, y no tienen el sello de la estampa antigua de cuando montaban a caballo. Además casi todas fuman y admiran al aviador como el súmmum (sic) del "sportsman". Los hombres de las anteriores generaciones no comprendieron a las mujeres, y quizá los hombres actuales las han comprendido, porque las han idealizado poco y las han tratado de igual a igual.

Tratan los jóvenes de hoy a las muchachas como camaradas y unos y otros practican mucho deporte, que convierte los nervios en acero y no permite tener muchas ideas trascendentales... Después de todo, ¡para qué!

Pío BARoja 
VIII

"Los chapelaundis. Zalacaín el aventurero visto por su autor"

(El Pueblo Vasco, San Sebastián, 12 de agosto de 1928: 2)

Amigos chapelaundis: hace veinte años, en San Juan Pie de Puerto comencé a escribir esta novela Zalacaín el aventurero, que ahora se está filmando en Behovia (sic). La escribí por entretenimiento para pasar el rato, y la terminé en unas pocas semanas.

Como la mayoría de mis libros, tuvo poco éxito. Al cabo de algún tiempo me pareció notar que en esa novela escrita a la ligera había puesto yo, sin proponérmelo, un ideal caro de mi vida (sic).

Todos tenemos ese fondo de ideal que se proyecta con mayor o menor claridad en forma de deseo o de sueño.

Ese Zalacaín, ese pequeño montañés que no tiene más patria que sus montes, ni más dogma que la conciencia de su vida y de su fuerza, que no quiere compararse con nadie, porque de la comparación no puede venir más que la tristeza y la envidia; ese fiero aldeano que no siente deseo de vivir en las grandes ciudades habitadas por príncipes y por esclavos, que resiste sin saber que resiste a la fuerza omnipotente del dinero y a la absorción romanojesuítica del mundo, me produce, a pesar de no ser quizá más que una sombra, un sentimiento de humana cordialidad.

Hoy ya no le considero como hijo mío, ni aun como allegado, sino como algo extraño y lejano a mí, y realmente así es.

Perico Larrañaga, que lo representa y le da nueva vida en la pantalla, está más cerca de él que su autor.

El autor se alejó hace tiempo de toda posibilidad heroica de pensamiento y de obra. No es ya más que un animal melancólico que se contenta con vivir con un poco de dignidad, cosa no siempre fácil. Los Zalacaín, si existen en esta época, tienen otra órbita y no se cruzan con nosotros.

Ahora, amigos chapelaundis, salud; y como no pensamos en ser heroicos sino en ser buenos beocios y buenos bebedores levantemos la copa alegremente y recordemos la frase humorística de Escalígero dedicada a los pueblos que confunden la v con la b:

"Felices populi quibus vivere est bibere (Felices pueblos para quienes vivir es beber)".

Pío BAROJA 
IX

"Opinión interesante. Pío Baroja y los deportes"

(La Prensa: diario de la mañana, Santa Cruz de Tenerife, jueves 13 de diciembre de 1930: 2)

¿La aviación? De ninguna manera. Hay que ir demasiado arriba. Además, en el aire, debe pasar un mal rato el estómago. Y hay que cuidar el estómago.

¿El fútbol? He presenciado un partido en Vera. Aquello da una cierta impresión grotesca. Como un baile cuando se ven los movimientos y no se oye la música. Sin embargo, creo en la necesidad del fútbol como remedio contra la desbordante -en lontananza- pasión taurina que es una de las tres grandes calamidades nacionales. Y no es necesario nombrar las otras dos, precisamente ahora cuando están en todos los labios.

¿La caza? Puedo hablar de ella con relativa experiencia. He tirado un tiro en cierta ocasión. Maté un pobre pajarillo, que, en el aire, frente a mi escopeta, adquirió la proporción de una avutarda. Luego, como en otras muchas ocasiones, deduje que no guardaba relación tanto estruendo con tan pequeña víctima.

¿Gimnasia? Sí. De estudiante concurrí a una escuela muscular de la Costanilla de los Ángeles. Por curiosidad, por ver cómo crecían los bíceps. Luego he sacado la conclusión de que la gimnasia es un procedimiento que sirve para poner la piel morena y abultados los brazos. Y pienso de disfrutar la misma salud orgánica, que también con la piel pálida se pue[de].

PíO BAROJA

\section{OBRAS CITADAS}

Alonso, Cecilio. "Pío Baroja en El Imparcial y en Nuevo Mundo: diez artículos ignorados". Montearabi 27 (1998): 31-91.

Ara Torralba, Juan Carlos. "Nota a la edición”. Pío Baroja. Obras completas. Vol. 16. Círculo de Lectores, 1999. 31-54.

Baroja, Pío. "Hacia la sombra". Pèl \& Ploma (edición castellana) 15 (Barcelona 1 de enero de 1901): 8.

Baroja, Pío. "El «Viejo Pastor»". Fuventud (Madrid 23 de febrero de 1902): 14. Baroja, Pío. "Víctor Hugo". Fuventud (Madrid 2 de marzo de 1902): 2 y 3.

Baroja, Pío. "Bandera, Patria, Estado". La Correspondencia de España (Madrid 14 de marzo de 1906): 6. 
Baroja, Pío. "Los futuros concejales: ¿qué piensan hacer?". La Mañana (Madrid, 6 de diciembre de 1909): 3.

Baroja, Pío. "Enquête mondiale sur l'avenir de la littérature". La Grande Revue 98 (París, diciembre 1918): 195-96.

Baroja, Pío, "Pío Baroja habla de mujeres, hombres y cine”. El Progreso (Santa Cruz de Tenerife, 2 de abril de 1928): 1.

Baroja, Pío. "Los chapelaundis: Zalacaín el aventurero visto por su autor". El Pueblo Vasco (San Sebastián, 12 de agosto de 1928): 2.

Baroja, Pío. "Opinión interesante: Pío Baroja y los deportes”. La Prensa (Santa Cruz de Tenerife, 13 de diciembre de 1930): 2.

Baroja, Pío. La decadencia de la cortesía y otros ensayos. Barcelona: RAID, 1956.

Baroja, Pío. Escritos de juventud. Prólogo y selección de Manuel Longares. Madrid: Cuadernos para el Diálogo, 1972.

Baroja, Pío. Hojas sueltas. Prólogo y notas de Luis Urrutia. 2 vols. Madrid: Caro Raggio, 1973.

Baroja, Pío. Obras completas. Ed. José-Carlos Mainer. Revisión de textos por Juan Carlos Ara Torralba. 16 vols. Barcelona: Círculo de Lectores, 1997-1999.

Baroja, Pío. Desde el exilio: los artículos inéditos publicados en La Nación de Buenos Aires. Ed. Miguel Ángel García de Juan. Madrid: Caro Raggio, 1999.

Baroja, Pío. Libertad frente a sumisión: las colaboraciones periodísticas publicadas en España durante 1938. Ed. Miguel Ángel García de Juan. Madrid: Caro Raggio, 2001.

Baroja, Pío. Los inéditos de HOY: los artículos inéditos publicados en HOY de México. Ed. Miguel Ángel García de Juan. Madrid: Caro Raggio, 2003.

Baroja, Pío. Corresponsalía de guerra y otros textos olvidados. Recopilación, introducción y notas de Miguel Ángel García de Juan. Madrid: Caro Raggio, 2014.

Celma Valero, María del Pilar. Literatura y periodismo en las revistas de fin de siglo: estudio e indices. Madrid: Júcar, 1991.

De Ancos Morales, Beatriz. Pio Baroja: literatura y periodismo en su obra. Madrid: Fundación Universitaria Española, 1998.

Lafont, Renée. "Les intelectuels espagnols et la Guerre". La Renaissance politique, littéraire et artistique (París, 20 marzo 1915): 13-18.

Sánchez Granjel, Luis. La Generación del 98. Salamanca: Anaya, 1973.

Sánchez-Ostiz, Miguel. Pío Baroja, a escena. Madrid: Espasa-Calpe, 2006.

Seoane, María Cruz, y María Dolores Sáiz. Historia del periodismo español. 3 vols. Madrid: Alianza, 1996. 